\title{
ANALISIS LEVEL KESIAPAN UNIVERSITAS MENUJU KAMPUS HIJAU DARI ASPEK ENERGI BERDASARKAN TIGA STANDAR PENGUKURAN
}

\author{
Nundang Busaeri \\ Teknik Elektro Universitas Siliwangi \\ email: nundangb@unsil.ac.id
}

\begin{abstract}
The University building is a building that should be based on the concept of green building, as an effort to reduce carbon production and optimizing energy use. In this article discusses the readiness of a university to the concept of a green campus based on three standard measurements. The research object is the University of Siliwangi (UNSIL), standard of measurement using the UI Green Metric, United Nations Environment Programme (UNEAP) and Greenship version 1.1. Measurements are limited to the energy aspect only. The results of the measurement obtained that Silwiangi University still has a low scor of the three approaches where on approach using the UI Green Matric, score Energy Aspects were acquired at the level of 7\%, then get the score 5 of the value ideal 15 on UNEP approach and score 23 on Greenship's approach version 1.1. New Renewable Energy Resources program for UNSIL campus is required in achieving green campus, and conservation and efficiency programmes to reduce greenhouse gas emissions are the priority of the campus.
\end{abstract}

Keywords: Green Campus, Energy, UNEP, UI Green Matrik.

\begin{abstract}
Abstrak
Gedung universitas merupakan bangunan yang selayaknya beroreintasi pada konsep bangunan hijau, sebagai upaya mengurangi produksi karbon dan optimalisasi penggunaan energi. Pada artikel ini membahas kesiapan sebuah universitas menuju konsep kampus hijau berdasarkan tiga standar pengukuran. Objek penelitian adalah Universitas Siliwangi, Standar pengukuran menggunakan UI Green Metric, United Nations Environment Programme (UNEAP) dan Greenship version 1.1. pengukuran hanya dibatasi pada aspek energi saja. Hasil pengukuran diperoleh bahwa Universitas Silwiangi masih memiliki scor rendah dari ketiga pendekatan di mana pada pendekatan menggunakan UI green matric, score aspek energi diperoleh pada level 7\%, kemudian mendapatkan score 5 dari nilai idela 15 pada pendekatan UNEP dan score 23 pada pendekatan greenship version 1.1. Program penyediaan sumber energi baru terbarukan untuk kampus UNSIL diperlukan dalam mencapai green campus, selain itu program konservasi dan efisiensi untuk mengurangi emisi gas rumah kaca menjadi prioritas kampus
\end{abstract}

Kata Kunci: Kampus hijau, energi, UNEP, UI Green Matrik.

\section{PENDAhULUAN}

Green-Campus merupakan program internasional untuk mewujudkan cara mengendalikan program pendidikan di kampus dalam menghadapi dan menyelesaikan isu lingkungan melalui program pendidikan dan penelitian yang inovasi dan implementasi hasilnya secara berkelanjutan di kampus [1]. Green campus pada pembentukan strateginya tetap mengacu pada teori berkelanjutan [2], [3], [4], [5], [6], yaitu terdiri dari lingkungan, sosial dan ekonomi [7].

Pertumbuhan perguruan tinggi di Indonesia sangat pesat. Fakta pertumbuhan perguruan tinggi di Indonesia adalah satu perguruan tinggi lahir setiap dua hari [8]. Jumlah mahasiswa di Indonesia mencapai 6.924.511 orang atau lebih banyak dibandingkan penduduk Singapura. Total jumlah bidang ilmu adalah 20.516 jurusan. Bidang ilmu yang terbanyak adalah teknik yaitu mencapai 4.634 [9].

Perekonomian yang maju menuntut peningkatan efisiensi penggunaan energi salah satunya di perguruan tinggi [6]. $\mathrm{H}$. Tan, et al (2014) mengangkat masalah yang terjadi di China, yaitu bagaimana mewujudkan green campus seiring dengan pertumbuhan Universitas dan sekolah di china yang setiap tahun meningkat, sementara kondisi tersebut tidak diimbangi dengan jumlah staff yang dibutuhkan. H. Tan, et al menemukan fakta bahwa, Green kampus dapat dicapai dengan dimulai dari rancangan strategi dari top-level, seperti pengolah departemen di universitas hingga menteri nasional terkait, dan juga beberapa dukungan jangka panjang agar tercapai green campus tersebut [6].

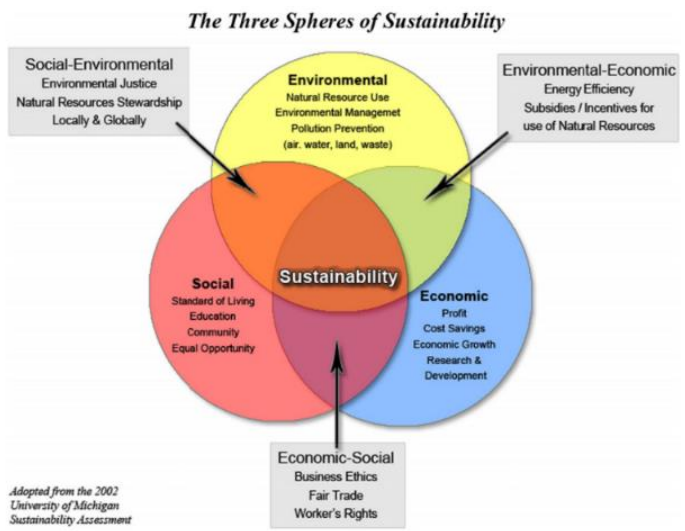

Gambar. 1. Bidang fundamental dari pembangunan berkelanjutan [7]

Gambar 02 menunjukkan 7 tahapan untuk mencapai green campus berdasarkan buku pedoman program green campus [1]. 7 tahapan itu adalah pembentukan dewan green campus yang didukung dengan 6 tahapan lainnya, yaitu pengamatan lingkungan, perencanaan aksi, monitoring dan evaluation, koneksi untuk belajar di kampus, informasi dan keterlibatan, pedoman untuk membangun green campus (Gambar 2). 


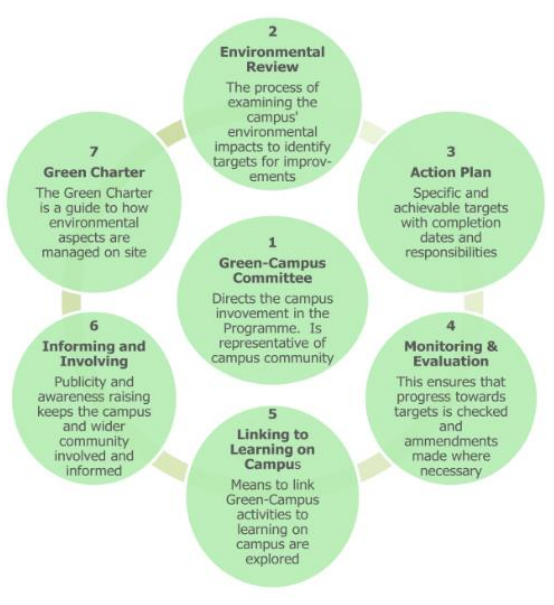

Gambar 2. Tujuh tahapan pada program green campus [1]

E. A. Hopkins, et al (2016) mengungkapkan bahwa umumnya halangan dalam pengambilan keputusan untuk mewujudkan green campus di antaranya adalah kurangnya perhatian dan kesadaran di antara pemegang keputusan, rendahnya insentif, tidak adanya kompetisi kebijakan (champions), kebijakan keuangan yang kurang mendukung [10]. Hal ini ditemukan di dalam [9]. Kemudian E. A. Hopkins, et al menemukan bahwa halangan tersebut dapat ditangani dengan review persepsi mahasiswa, mendorong pemahaman kepada pemilik universitas atau pihak eksekutif universitas, memasarkan inisiatif pembangunan green campus, dan setiap pemegang kebijakan harus menjadi bagian dari kolaborasi untuk mengurangi halangan tersebut.

R. Dagiliūté, et al tahun 2018) telah membandingkan sikap mahasiswa dari universitas dengan green campus dengan mahasiswa dari universitas non-green campus. Hasilnya menunjukkan bahwa tidak ada perbedaan yang signifikan dari aspek keberlanjutan secara umum. Tetapi meskipun demikian, mahasiswa lebih menginginkan kampus mereka dideklarasikan menjadi kampus hijau.

Penilaian katagori green campus yang umum digunakan saat ini adalah UI GreenMetric dan UNEP's Greening University Toolkit, Greenship [11], [12]. Penilaian berdasarkan UI GreenMetric [2] meliputi variabel penilaian di antaranya adalah Setting and Infrastructure (SI), Energy and Climate Change (EC), Waste (WS), Water (WR), Transportation (TR), Education (ED) [13]. Pada penilaian berdasarkan UNEP's Greening University meliputi variabel penilaian di antaranya adalah Energy, Carbon and Climate Change, water, waste, Biodiversity and Ecosystem Service, Planning, Design and Development, Procurement, Green Office, Green Lab, Green IT, Transport [11]. Pada penilaian berdasarkan Greenship version 1.1 UNEP's Greening University meliputi variabel penilaian di antaranya pengembangan lokasi yang tepat, efisiensi dan konservasi energi, konservasi air, siklus dan sumber daya material, kesehatan dan kenyamanan dalam ruangan, pengelolaan lingkungan bangunan [14].

Penelitian sebelumnya membahas mengenai ketahanan air dalam standar penilaian kampus hijau dengan membandingkan dari tiga standar penilaian, yaitu UI GreenMatric, Greenship (for Existing Buildings), STARS [15]. Kemudian model pengukuran diusulkan untuk mengetahui konsumsi energi secara online [16].

UI GreenMatric merupakan buku panduan penilaian green campus [2] dengan Variabel penilaian terdiri 6 komponen, yaitu Penataan and Infrastruktur (SI), Energi dan perubahan iklim (EC), Limbah (WS), Air (WR), Transportasi (TR), Pendidikan (ED). Selain UI greenmetrik. UNEP's Greening University Toolkit adalah penilaian green campus menggunakan 10 variabel penilaian [11], [17]. Variabel tersebut adalah (1) Energy, Carbon, and Climate Change, (2) water, (3) waste, (4) Biodiversity and Ecosystem Service, (5) Planning, Design and Development, (5) Procurement, (6) Green Office, (7) Green Office, (8) Green Lab, (9) Green IT, (10) Transport. sementara beberapa peneliti menemukan fakta keberhasilan program green campus juga dipengaruhi oleh tingkat kesadaran pimpinan dan pemilik universitas hingga mahasiswa yang berdampak kepada perilaku yang keberhasilan mewujudkan universitas berkonsep green campus [6]. Variabel berdasarkan standar penilaian Greenship Rating Tools for Existing Building Version 1.0 adalah Appropriate Site Development (ASD), Energy Efficiency and Conservation (EEC), Water Conservation (WAC), Material Resources and Cycle (MRC), Indoor Health and Comfort (IHC), Building Environment Management (BEM) [18].

\section{METODE}

Analisis green campus bedasarkan aspek energi di kampus menggunakan tiga standar pengukuran, yaitu UI GreenMatric, United Nations Environment Programme (UNAP), Greenship Version 1.1. Parameter

A. Pengukuran kampus hijau berdasarkan aspek energi berdasarkan UI GreenMatric.

Pengukuran green campus dari aspek energi berdasarkan UI Green Matric meliputi delapan kriteria, yaitu:

1. Penggunaan peralatan hemat energi (energy efficient appliances usage)

2. Implementasi gedung pintar (smart building implementation)

3. Penggunaan energi baru terbarukan (renewable energy usage)

4. Rasio total penggunaan listrik terhadap populasi kampus (The ratio of total electricity usage towards campus population)

5. Rasio produksi energi terbarukan terhadap penggunaan energi (the ratio of renewable energy produce towards energy usage)

6. Elemen implementasi bangunan hijau (element of green building implementation)

7. Program pengurangan emisi gas rumah kaca (greenhouse gas emission reduction program).

Penilaian aspek energi dari kampus universitas Siliwangi menggunakan pendekatan dari 3 jenis standar pengukuran, yaitu UI GreenMatric, UNEP, Greenship version 1.1. dari tiga standar pengukuran tersebut, dipilih variabel pengukuran pada energy subcategory.

Produksi karbon per tahun pada lingkungan kampus dapat ditentukan dengan persamaan (1).

$$
O S a=\sum C a-\sum G F a
$$

Di mana, OSa adalah area terbuka $\left(\mathrm{m}^{2}\right), \mathrm{Ca}$ adalah total area kampus $\left(\mathrm{m}^{2}\right), \mathrm{GFa}$ adalah total area bangunan $\left(\mathrm{m}^{2}\right)$. 
Jumlah okupasi di kampus merupakan penjumlahan dari mahasiswa, dosen, dan staft yang ada di kampus, oleh karena itu, total okupasi kampus dihitung menggunakan persamaan berikut:

$$
\sum P=\sum S t d-\sum F T s t d+\sum A+\sum S t f
$$

Di mana $P$ adalah jumlah orang di kampus, Std adalah jumlah mahasiswa, termasuk mahasiswa paroh waktu, $A$ adalah jumlah akademik, dosen, staft, dan Stf adalah pegawai administrasi akademik. Sementara emisi karbon yang berasal dari penggunaan listrik per tahun, penggunaan transportasi berupa bus per tahun, jumlah mobil dan kendaraan motor yang masuk dan keluar kampus per tahun.

Emisi karbon yang dikeluarkan akibat penggunaan energi listrik dihitung menggunakan persamaan berikut:

$$
\mathrm{CO}_{2}(\text { electricity })=\frac{E \times 0.84}{1000}(\mathrm{MT})
$$

Di mana $\mathrm{CO}_{2}$ (electricity) adalah jumlah emisi karbon $\left(\mathrm{CO}_{2}\right)$ yang diproduksi dalam Metric Ton (MT), E adalah energi per tahun $(\mathrm{KWh} / \mathrm{y})$, Emisi karbon yang dikeluarkan akibat penggunaan kendaraan bus kampus dihitung menggunakan persamaan berikut:

$$
\mathrm{CO}_{2}(\text { Bus })=\frac{N_{\text {bus }} \times L \times D \times 240 \times 0.01}{100}(\mathrm{MT})
$$

Di mana $\mathrm{CO}_{2}$ (Bus) adalah emisi karbon yang diproduksi dari bus kampus per tahun (MT), $\mathrm{N}_{\text {bus }}$ adalah Jumlah bus antar-jemput di Universitas Anda, L adalah total perjalanan untuk layanan bus antar-jemput setiap hari, D adalah perkiraan jarak perjalanan kendaraan setiap hari di dalam kampus (dalam kilometer).

Emisi karbon yang dikeluarkan akibat penggunaan kendaraan mobil yang masuk dan keluar kampus dihitung menggunakan persamaan berikut

$$
\mathrm{CO}_{2}(\mathrm{car})=\frac{N_{\text {car }} \times 2 \times D \times 240 \times 0.02}{100}
$$

$\mathrm{CO}_{2}$ (car) adalah emisi karbon yang diproduksi dari kendaraan mobil per tahun (MT), $\mathrm{N}_{\text {car }}$ adalah kendaraan mobil yang masuk dan keluar kampus, D adalah perkiraan jarak perjalanan kendaraan setiap hari di dalam kampus (dalam kilometer), (240/100)* 0.02 adalah konstanta.

Emisi karbon yang dikeluarkan akibat penggunaan kendaraan motor yang masuk dan keluar kampus dihitung menggunakan persamaan berikut;

$$
\mathrm{CO}_{2}(\text { motorcycle })=\frac{N_{\text {motorcycle }} \times 2 \times D \times 240 \times 0.01}{100}
$$

$\mathrm{CO}_{2}$ (motorcycle) adalah jumlah emisi karbon yang diproduksi dari kendaraan bermotor yang ada di kampus (MT), $\mathrm{N}_{\text {motorcycle }}$ adalah Jumlah sepeda motor yang memasuki Universitas per tahun, D adalah perkiraan jarak tempuh kendaraan setiap hari di dalam kampus (dalam kilometer), $(240 / 100)^{*} 0.01$ dalah konstanta.

Total emisi karbon di kampus per tahun dihitung menggunakan persamaan berikut:

$$
\begin{aligned}
\mathrm{CO}_{2}(\text { emission })= & \left(\mathrm{CO}_{2}(\text { electricity })+\mathrm{CO}_{2}(\mathrm{bus})+\mathrm{CO}_{2}(\text { car })\right. \\
& \left.+\mathrm{CO}_{2}(\text { motorcycle })\right)(\mathrm{MT})
\end{aligned}
$$

\section{B. Pengukuran green campus dari aspek energi berdasarkan UNEP}

United Nations Environment Programme (UNEP) memiliki 10 catagory, yaitu energi, karbon, dan perubahan iklim, air, limbah, keanekaragaman hayati dan layanan ekosistem, perencanaan, desain dan pengembangan, pengadaan, kantor hijau, lab hijau, IT hijau, transportasi. pada paper ini digunakan energi subkatagori. Energi subkategori UNEP terdiri dari konservasi energi, efisiensi energi, energi terbarukan dan alternatif.

Variabel konservasi energi memiliki nilai maksimum 45 point. Masing masing subkatagori adalah pekerjaan manajer energi, standar efisiensi energi untuk konstruksi dan perbaikan baru, standar pembelian efisiensi energi, pelatihan konservasi energi staf, peningkatan pemanfaatan ruang untuk menghindari konstruksi baru atau pemanasan / pendinginan ruang yang kurang dimanfaatkan, kebijakan kenyamanan termal, kesulitan keuangan untuk menetapkan biaya energi yang dikeluarkan - dan penghematan yang dicapai - ke pusatpusat biaya yang bertanggung jawab, program kesadaran energi / perubahan iklim, pembentukan jaringan "juara energi" di seluruh gedung kampus.

Variabel energy efficiency memiliki nilai maksimum 35 point. efisiensi energi variabel menyertakan audit energi terperinci untuk mengidentifikasi area prority, recommissioning berkala dan tuning bangunan untuk mengoptimalkan efisiensi energi, pencahayaan gedung retrofit, pemanas, ventilasi dan pendingin udara (HVAC) ventilasi laboratorium dan lemari asam, pemasangan manajemen gedung dan sistem kontrol ( BMCS) dan subpengukuran untuk penggunaan energi bangunan utama, tampilan penggunaan energi.

Variabel renewable and alternative energi memiliki nilai maksimum 25 point, variael ini meliputi pembelian "tenaga hijau" bersertifikat, pemasangan fotovoltaik, angin, biomassa. sistem. Pemasangan kogenerasi dan pemicu, penggantian bahan bakar, program revegetasi yang dikelola universitas untuk mengimbangi emisi rumah kaca.

\section{Pengukuran green campus dari aspek energi berdasarkan Greenship versi 1.1}

Pengukuran greenship versi 1.1 terdiri dari 8 variabel, yaitu kebijakan dan rencana manajemen energi, kinerja energi bangunan minimum, efisiensi kinerja energi bangunan yang dioptimalkan, pengujian, komisioning ulang atau retrocommissioning, kinerja energi sistem, pemantauan dan kontrol energi, operasi dan pemeliharaan, energi terbarukan di lokasi.

Table 1 adalah daftar subcatagory berdasarkan standar pengukuran yang digunakan. UNEP memiliki variabel yang lebih sedikit dari pada Greenship ataupun UI GreenMatric.

Table 1. Variable of energy subcategory for varios standar measurment

\begin{tabular}{cll}
\hline Standart & Code & \multicolumn{1}{c}{ Subcategory } \\
\hline & EC 1 & Energy efficient appliances usage \\
\cline { 2 - 3 } & EC 2 & Smart building implementation \\
\cline { 2 - 3 } EC 3 & Renewable energy usage \\
\cline { 2 - 3 } UI GreenMetric 4 & $\begin{array}{l}\text { The ratio of total electricity usage } \\
\text { towards campus population }\end{array}$ \\
\cline { 2 - 3 } & EC 5 & $\begin{array}{l}\text { The ratio of renewable energy } \\
\text { produce towards energy usage }\end{array}$ \\
\cline { 2 - 3 } & EC 6 & $\begin{array}{l}\text { Element of green building } \\
\text { implementation }\end{array}$ \\
\cline { 2 - 3 } & EC 7 & $\begin{array}{l}\text { Greenhouse gas emission reduction } \\
\text { program }\end{array}$ \\
\cline { 2 - 3 } & EC 8 & $\begin{array}{l}\text { The ratio of total carbon footprint } \\
\text { towards campus population }\end{array}$ \\
\hline
\end{tabular}




\begin{tabular}{|c|c|c|}
\hline \multirow{3}{*}{ UNEP } & 1 & Energy Conservation \\
\hline & 2 & Energy efficiency \\
\hline & 3 & Renewable and alternative energy \\
\hline \multirow{8}{*}{$\begin{array}{l}\text { Greenship } \\
\text { Version } 1.1\end{array}$} & P1 & $\begin{array}{l}\text { Policy and Energy Management } \\
\text { Plan }\end{array}$ \\
\hline & P2 & $\begin{array}{lll}\text { Minimum } & \text { building } & \text { Energy } \\
\text { Performance } & & \end{array}$ \\
\hline & EEC1 & $\begin{array}{l}\text { Optimized Efficiency } \text { Building } \\
\text { Energy Performance }\end{array}$ \\
\hline & EEC2 & $\begin{array}{l}\text { Testing, Recommissioning or } \\
\text { Retrocommissioning }\end{array}$ \\
\hline & EEC3 & System Energy Performance \\
\hline & EEC4 & Energi Monitoring \& Control \\
\hline & EEC5 & Operation and Maintenance \\
\hline & EEC6 & On Site Renewable Energy \\
\hline
\end{tabular}

\section{HASIL DAN PEMBAHASAN}

Hasil analisis dari data yang tersedia di kampus universitas Siliwangi, setelah dilakukan analisis penilaian berdasarkan menggunakan UI GreenMatric, diperoleh bahwa kampus UNSIL masih kurang layak untuk dikatakan sebagai green campus, hal ini terlihat bahwa scor ideal adalah 2100 point, sementara pada kampus UNSIL hanya diperoleh score 578. Artinya bahwa masih banyak hal yang harus diperbaiki. Nilai terendah adalah pada variabel EC3 dan EC7. Artinya kampus UNSIL harus segera memiliki sumber energi baru terbarukan (EC3) dan program pengurangan emisi gas rumah kaca (EC7). Meskipun variabel lainnya terdapat nilai, tetapi nilai yang diperoleh masih di bawah standar.

Table 2. Tabulasi data pengukuran berdasarkan UI GreenMatric pada aspek energy

\begin{tabular}{lcc}
\hline Code & Maximum score & Measurment score \\
\hline EC 1 & 200 & 100 \\
\hline EC 2 & 300 & 45 \\
\hline EC 3 & 300 & 0 \\
\hline EC 4 & 300 & 170 \\
\hline EC 5 & 200 & 100 \\
\hline EC 6 & 300 & 150 \\
\hline EC 7 & 200 & 0 \\
\hline EC 8 & 300 & 12.3 \\
\hline Score & $\mathbf{2 1 0 0}$ & $\mathbf{5 7 8}$ \\
\hline
\end{tabular}

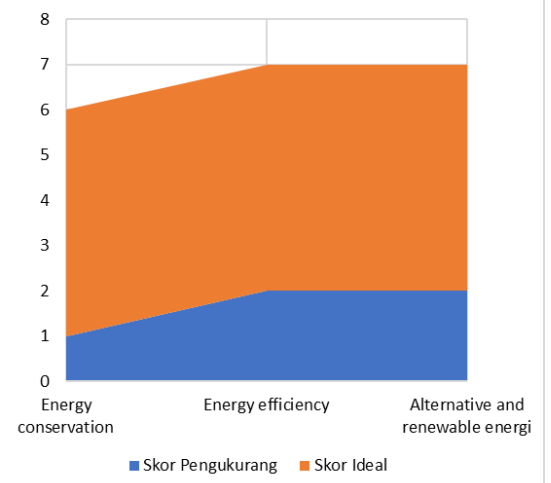

Gambar 03. Pengukurang aspek energi berdasarkan UI GreenMatric

Analisis menggunakan standar penilaian UNEP, diketahui bahwa kampus UNSIL memiliki penilaian yang rendah dari semua variabel. Dari total tiga variabel, nilai terendah adalah variabel 1, yaitu Energy conservation dengan point 1 dari nilai maksimum 5 , kemudian nilai 2 pada variabel energi efficiency yaitu bernilai 2 dari nilai maksimum 5 . Variabel Renewable and alternative energi adalah bernilai 2 dari nilai maksimum 5 .

Table 3. Tabulasi data pengukuran berdasarkan UNEP pada aspek energy

\begin{tabular}{lllll}
\hline No. & Sub catagory & Nilai & $\begin{array}{l}\text { Measurment } \\
\text { score }\end{array}$ & $\begin{array}{l}\text { Ideal } \\
\text { score }\end{array}$ \\
\hline 1 & $\begin{array}{l}\text { Energy } \\
\text { conservation }\end{array}$ & very poor & 1 & 5 \\
\hline 2 & $\begin{array}{l}\text { Energy } \\
\text { efficiency }\end{array}$ & poor & 2 & 5 \\
\hline 3 & $\begin{array}{l}\text { Alternative and } \\
\text { renewable } \\
\text { energi }\end{array}$ & poor & 2 & 5 \\
\hline
\end{tabular}

Total Skor very poor 5

15

Dari gambar 04. Dapat disimpulkan bahwa diperlukan program-program yang segera dilaksanakan terkait dengan konservasi energi kampus, efficiency energi kampus dan pembuatan sumber energi baru terbarukan sebagai energi alternatif.

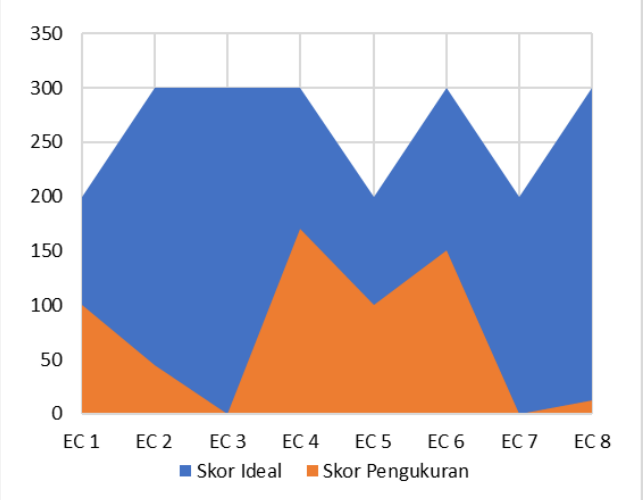

Gambar 04. Pengukurang aspek energi berdasarkan UNEP

Gambar 05 menunjukkan hasil analisis pengukuran berdasarkan Greenship versi 1.1, diperoleh bahwa score yang dapat dicapai oleh UNSIL adalah 23 dan dari score maximum 36. Artinya UNSIL masih belum mencapai catagory green campus. Dari tujuh variabel pada penilaia Greenship version 1.1, variabel EEC6 memperoleh nilai zero, artinya UNSIL belum memiliki sumber energi baru terbarukan sebagai energi alternatif. Meskipun demikian, berdasarkan Tabel 4, pada variabel EEC1 hasil pengukuran mendapatkan score 14 dari nilai maksimum 16, artinya UNSIL telah ada di jalur yang benar dalam melakukan Optimizing Efficiency Building Energy Performance. Sementara itu variabel yang lain diperlukan perhatian untuk mencapai nilai yang lebih baik. 


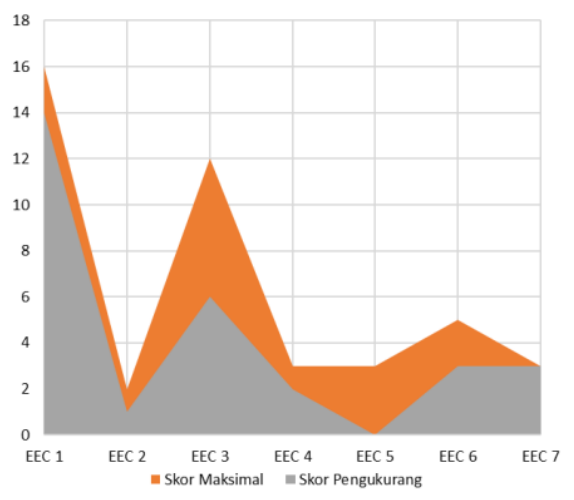

Gambar 05. Pengukurang aspek energi berdasarkan Greenship v.1.1.

Table 4. Tabulasi data pengukuran berdasarkan Greenship version 1.1 pada aspek energy

\begin{tabular}{clcc}
\hline Kode & $\begin{array}{l}\text { Energy Efficiency } \\
\text { and Conservation }\end{array}$ & $\begin{array}{c}\text { Maximum } \\
\text { score }\end{array}$ & $\begin{array}{c}\text { Measurment } \\
\text { score }\end{array}$ \\
\hline EEC 1 & $\begin{array}{l}\text { Optimized } \\
\text { Efficiency Building } \\
\text { Energy Performance }\end{array}$ & 16 & 14 \\
\hline EEC 2 & $\begin{array}{l}\text { Testing, } \\
\text { Recommissioning or } \\
\text { Retrocommissioning }\end{array}$ & 2 & 1 \\
\hline EEC 3 & $\begin{array}{l}\text { System Energy } \\
\text { Performance }\end{array}$ & 12 & 6 \\
\hline EEC 4 & $\begin{array}{l}\text { Energi Monitoring } \\
\text { \& Control }\end{array}$ & 3 & 2 \\
\hline EEC 5 & $\begin{array}{l}\text { Operation and } \\
\text { Maintenance }\end{array}$ & 3 & 3 \\
\hline EEC 6 & $\begin{array}{l}\text { On Site Renewable } \\
\text { Energy }\end{array}$ & 5 & 0 \\
\hline EEC 7 & $\begin{array}{l}\text { Less Energy } \\
\text { Emission }\end{array}$ & 3 & 3 \\
\hline & $\quad$ Total & $\mathbf{3 6}$ & $\mathbf{2 3}$ \\
\hline
\end{tabular}

\section{KESIMPULAN}

Kesimpulan dari analisi penilaian score green campus berdasarkan aspek energi dengan menggunakan tiga pendekatan penilaian, diperoleh beebrapa fakta yang dapat diberikan high light, di antaranya bahwa berdasarkan standar penilaian dengan UI GreenMatric, UNSIL harus segera memiliki sumber energi baru terbarukan dan program pengurangan emisi gas rumah kaca dengan menyediakan program resmi untuk mengurangi emisi gas rumah kaca yang dapat diterapkan pada sistem tata udara gedung dan laboratorium.

Berdasarkan standar penilaian dengan UNEP, UNSIL memperoleh nilai yang rendah tiga variabel. Nilai terendah adalah variabel 1, yaitu Energy conservation. Artinya UNSIL harus segera membuat program conservasi energi, efficiency energi dan menyediakan energi baru terbarukan sebagai sumber alternative energi.

Berdasarkan standar penilaian dengan Greenship version 1.1, UNSIL segera memiliki sumber energi baru terbarukan sebagai energi alternatif. Meskipun demikian, berdasarkan UNSIL telah ada di jalur yang benar dalam mewujudkan green campus dengan melakukan melakukan Optimizing Efficiency Building Energy Performance.

\section{UCAPAN TERIMA KASIH}

Ucapan terima kasih ini ditujukan kepada Program Studi Teknik Elektro, Fakutlas Teknik, Universitas Siliwangi atas dukungan yang telah diberikan sehingga penelitian ini terlaksana.

\section{REFERENSI}

[9] I. Nirmala and A. N. R. Attamimi, "Statistik Pendidikan Tinggi," 2017.

[10] E. A. Hopkins, "Barriers to adoption of campus green building policies," Smart Sustain. Built Environ., vol. 5, no. 4, pp. 340-351, 2016.

[11] S. Sisriany and I. S. Fatimah, "Green Campus Study by using 10 UNEP's Green University Toolkit Criteria in IPB Dramaga Campus," IOP Conf. Ser. Earth Environ. Sci., vol. 91, no. 1, pp. 0-7, 2017.

[12] Rejoni et al., "PENERAPAN SISTEM PERANGKAT PENILAIAN PADA," J. Lanskap Indones., vol. 8, pp. 14-27, 2016.

[13] "Guideline of UI GreenMetric World University Rangking 2016," no. March. UI GreenMatric Secretariat, 2016.

[14] "GREENSHIP EXISTING BUILDING Version 1.0." Green Bilding Council Indonesia, Jakarta, Indonesia, 2011.

[15] M. Wimala, B. Zirads, and R. Evelina, "Water Security in Green Campus Assessment Standard," 
E3S Web Conf., vol. 93, p. 02003, Apr. 2019.

[16] U. Alvi, F. Khuhawar, and B. Ashfaq, "Green Campus: Measurements and Modeling," in 20th International Multitopic Conference (INMIC'17), 2017, pp. 1-6.

[17] T. Universities and I. Green, "Greening Universities Toolkit V2.0 Transforming Universities Into Green and Sustainable Campuses: a Toolkit for Implementers Advance Copy."

[18] N. Firnando and A. Putra, "Penilaian Kriteria Green Building Pada Bangunan Gedung Rumah Sakit Universitas Sumatera Utara," pp. 1-16.

\section{BIOGRAFI PENULIS}

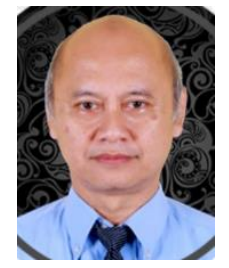

Nundang Busaeri, Lahir di Tasikmalaya, bekerja sebagai tenaga pengajar di Program Studi Teknik Elektro Universitas Siliwangi dengan bidang konsentrasi ilmu manajemen energi. 